\title{
GROUND VISCOUS EFFECT ON 3D FLOW STRUCTURE OF A COMPOUND WING-IN-GROUND EFFECT
}

\author{
S. Jamei, A. Maimun, N. Azwadi, M. M. Tofa, S. Mansor and A. Priyanto \\ ${ }^{\mathbf{1}}$ Faculty of Mechanical Engineering, Universiti Teknologi Malaysia \\ 81310, UTM Skudai, Johor, Malaysia \\ *Email: jsaeed2@live.utm.my \\ Phone: +607-553-5957; Fax: +607-553-5708
}

\begin{abstract}
The wing-in-ground-effect craft is a new means for traveling on rivers, lakes, and at sea between islands. In this study, the effect of boundary layers due to the ground viscous effect on the aerodynamic coefficients of the compound wing of a WIG craft was numerically investigated. The compound wing is divided into three parts, with one rectangular wing in the middle and two reverse taper wings with an anhedral angle at the sides. A realizable k- $\varepsilon$ turbulent model was used for modeling the flow around the wing area. The computational results of the compound wing for fixed ground were compared with the experimental data. The aerodynamic characteristics of the compound wing were examined via both fixed and moving ground for removing the boundary layers effect of the ground. Accordingly, the numerical result indicated that the lift and drag coefficients and lift to drag ratio are affected by the ground boundary layers while the moment coefficient and center of pressure of the compound wing showed little variation with respect to ground boundary conditions.
\end{abstract}

Keywords: Aerodynamics; boundary layer; compound wing; CFD simulation; WIG craft.

\section{INTRODUCTION}

Fast-marine transportation around and among islands and coastal areas has developed for many services such as passenger travel, military use and rescue. Wing-in-groundeffect (Ludwig, McGregor, Blowes, Benner, \& Mountjoy, 2002) vehicles are highspeed craft which are a promising option for both work and travel because of their economic benefits (Yun, Bliault, \& Doo, 2009). A WIG craft has two advantages compared with aircraft. First is the higher ram pressure because of trapping of the air flow around the stagnation point on the lower surface of the wing in proximity to the ground. Next, the induced drag is weaker because the wing is near the ground, so the tip vortex is trapped by the ground and reduces the strength of vortices (Abramowski, 2007). The effect of ground boundary layers on the performance of the wing-in-ground effect is a challenge for researchers (Marqués-Bruna, 2011; Saad \& Bari, 2013; Tahseen, Ishak, \& Rahman, 2013; Yang, Yang, \& Jia, 2010; Ying, Yang, \& Yang, 2010a, 2010b). Yang, Z. G. et al. (2010) showed an effective height decrease because of the rise of ground by using a displacement thickness which caused an over-estimation of the ground effect. A separation bubble was created on the ground when the ground was considered as a fixed boundary. The separation bubble could rise with reduced ground clearance and a higher angle of attack. As a result, the passageway of the air flow was reduced and then the ram effect decreased and lift would be underestimated. In addition, 
the separation bubble caused the stagnation point to move towards the leading edge and then the air flow on the upper surface of the wing had higher energy with lower adverse pressure gradients, where there was a delay on the separation at the trailing edge and stall angle as well (Yang, Lin, \& Yang, 2010). Yang, W. et al. (2010) illustrated that the separation bubble is developed more by the ground level than by the angle of attack. Ying et al. (2010a) demonstrated that the separation bubble was removed at a ground clearance greater than 0.2 , and that therefore the aerodynamic behavior of the air flow on fixed ground was similar to moving ground.

Yang and Yang (2009) tried to identify numerically the ground viscous effect on the wing-in-ground effect. They showed a negative lift coefficient and a rapid increase of drag coefficient with a small angle of attack $\left(\mathrm{AOA} \leq 4^{\circ}\right)$ in low ground clearance $(\mathrm{h} / \mathrm{c} \leq 0.1)$. At an angle of attack of $4^{\circ}$ and with different ground clearances, they reported a higher lift and lower drag for fixed ground compared to moving ground; but this difference reduced at higher ground clearance. The interaction of the boundary layer of fixed ground and the model when tested in a wind tunnel has a greater influence on the aerodynamic forces than in real flight (Borello et al., 1999). Therefore, the effect of the ground boundary layer in some testing should be removed, for example, in vehicle testing. The moving belt is one method to reduce this effect (Barber, Leonardi, \& Archer, 2002), although this method is not always feasible. Knowles, Donoghue, and Finnis (1994) believed that the boundary layer reduces the effective ground clearance of the wing, which improves the venture effect between the wing and ground. Therefore, flow velocities are accelerated, which results in lower pressure and higher downforce. Marshall, Newman, and Williams (2010) demonstrated the influence of the boundary layer on an inverted wing ground effect when there is no moving ground. They observed that a larger boundary layer induced stronger pressure and consequently smaller flow velocities. A larger downforce was recorded for a smaller boundary layer height because of the lower pressure suction surface. Jamei, Maimun, Mansor, Azwadi, and Priyanto (2012) numerically investigated the aerodynamic characteristics of a compound wing-in-ground effect. The compound wing is divided into two parts: the middle part as the rectangular wing and the side parts that are reverse taper wings with an anhedral angle. They showed that compound wings can create a greater reduction of downwash velocity and modify the pressure distribution on the lower side, which leads to a higher augmentation in the lift force. Also, the smaller distance between the wing tip of compound wings and the ground causes a reduction of drag because of the weaker tip vortex. In addition, the performance, fuel consumption and environmental impact of compound wings have been investigated by Jamei, Maimun, Mansor, Azwadi, and Priyanto (2011). The lower drag of compound wings allows a considerable reduction in fuel consumption, which could be an economic advantage. Accordingly, the $\mathrm{CO}_{2}$ emission related to compound wings is much less than that of a rectangular wing. According to the previous research, the effect of ground boundary layers on the aerodynamics of the wing is still a major objective for researchers. In this paper, the effect of ground viscous boundary layers on the aerodynamics coefficient of a compound wing-in-ground effect (Jamei et al., 2012) was numerically investigated. Two ground boundaries were used in the simulations, fixed ground and moving ground. In this research, the lift and drag coefficient, lift to drag ratio, moment coefficient and center of pressure of the present compound wing were measured, as these could be affected by the ground viscous effect. The pressure and velocity distributions as well as the aerodynamic coefficients of the compound wing were analyzed for each ground boundary. 


\section{CFD NUMERICAL STUDY}

The numerical study was performed on a compound wing with NACA6409 airfoil section. The principal dimensions of the compound wing (Figure 1) are shown in Table 1 (Jamei et al., 2012). These simulations were prepared with respect to different angles of attack and ground clearances $(\mathrm{h} / \mathrm{c})$, aspect ratio 1.25 , and velocity of airflow 25.5 $\mathrm{m} / \mathrm{s}$, in addition to which two ground boundary conditions were considered, fixed and moving. Ground level (h) is defined by the distance between the center of the trailing edge of the wing and the ground surface. CFD methods are based on the solution of Navier-Stokes equations by using the finite volume method (FVM). Many flows of engineering significance are turbulent, especially in aerospace applications. The flow field around the compound wing was assumed to be steady-state and incompressible by means of a realizable $k-\varepsilon$ turbulent model. Fluent software was employed for the CFD simulations. Shih, Liou, Shabbir, Yang, and Zhu (1995) recommended a realizable $k-\varepsilon$ turbulent model which used a new turbulent viscosity formula and a new dissipation rate equation $(\varepsilon)$ according to the dynamic equation of the mean-square vortices fluctuation. The transport equations for the turbulent kinetic energy $(k)$ and turbulent dissipation energy $(\varepsilon)$ are expressed as follows:

$$
\frac{\partial}{\partial t}(\rho k)+\frac{\partial}{\partial x_{j}}\left(\rho k u_{j)}=\frac{\partial}{\partial x_{j}}\left[\left(\mu+\frac{\mu_{t}}{\sigma_{k}}\right) \frac{\partial k}{\partial x_{j}}\right]+G_{k}+G_{b}-\rho \varepsilon-Y_{M}+S_{k}\right.
$$

and

$$
\begin{gathered}
\frac{\partial}{\partial t}(\rho \varepsilon)+\frac{\partial}{\partial x_{j}}\left(\rho u_{j}\right)=\frac{\partial}{\partial x_{j}}\left[\left(\mu+\frac{\mu_{t}}{\sigma_{\varepsilon}}\right) \frac{\partial \varepsilon}{\partial x_{j}}\right]+\rho C_{1} S \varepsilon-\rho C_{2} \frac{\varepsilon^{2}}{k+\sqrt{v \varepsilon}} \\
+C_{1 \varepsilon} \frac{\varepsilon}{k} C_{3 \varepsilon} G_{b}+S_{\varepsilon} \\
C_{1}=\max \left[0.43, \frac{\eta}{\eta+5}\right], \eta=\frac{k}{\varepsilon}, S=\sqrt{2 S_{i j} S_{i j}}
\end{gathered}
$$

where $S_{k}$ and $\mathrm{S}_{\varepsilon}$ are user-defined source terms, $\mathrm{C}_{1 \varepsilon}, \mathrm{C}_{2}, \mathrm{C}_{3 \varepsilon}, \sigma_{k}$ and $\sigma_{\varepsilon}$ are the adaptable constants.

The aerodynamic coefficients and center of pressure in this numerical study were determined as follows:

$$
C_{L}=\frac{L}{0.5 \rho U^{2} A}, \quad C_{D}=\frac{D}{0.5 \rho U^{2} A}, \quad C_{M}=\frac{M}{0.5 \rho U^{2} A c} \text { and } X_{C P}=0.25+\frac{C_{M}}{C_{L} \cos \alpha+C_{D} \sin \alpha} \text {. }
$$

In this study, the standard wall functions (Launder \& Spalding, 1974) were employed in the numerical simulation. The wall functions have certain advantages, such as being less time-consuming, reducing the number of meshes near the walls such as the wing, being cost-effective and having acceptable accuracy. Based on the current simulation, the mesh number was around 4,500,000, which yielded acceptable convergence. 


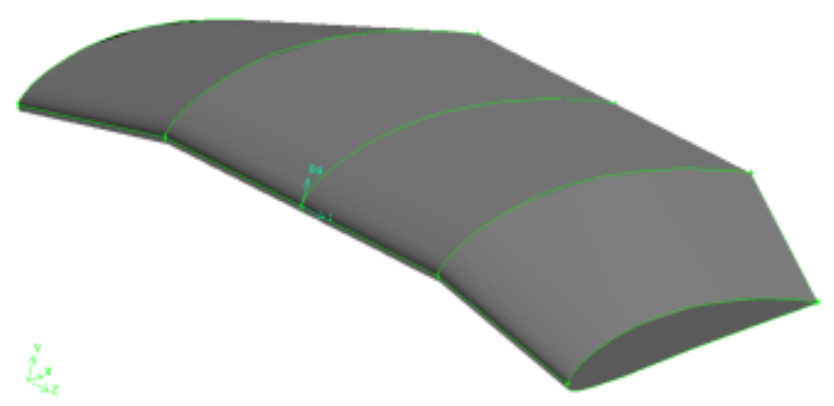

(a)

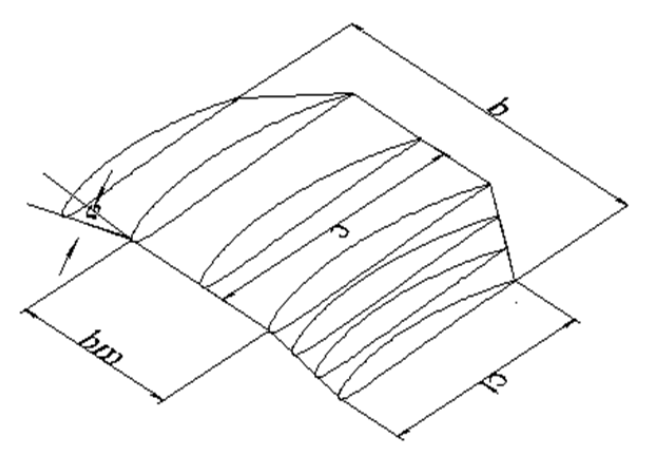

(b)

Figure 1. (a) Compound wing; (b) geometry of the compound wing.

Table 1. Principal dimensions of the compound wing.

\begin{tabular}{lc}
\hline \multicolumn{1}{c}{ Dimensions of compound wing } \\
\hline Total wing span $(\mathrm{b})$ & $250 \mathrm{~mm}$ \\
Root chord length $(\mathrm{c})$ & $200 \mathrm{~mm}$ \\
Middle wing span $\left(\mathrm{b}_{\mathrm{m}}\right)$ & 125 \\
Taper ratio $\left(\mathrm{c} / \mathrm{c}_{\mathrm{t}}\right)$ & 1.25 \\
Anhedral angle $(\mathrm{a})$ & $13^{\circ}$ \\
\hline
\end{tabular}

VALIDATION OF NUMERICAL STUDY

In this study, the CFD simulation was validated with experimental data by using the low speed wind tunnel at the Universiti Teknologi Malaysia. Figure 2a-b illustrates the aerodynamic coefficients of the compound wing for fixed ground at a ground clearance of 0.15 , and shows that the numerical and experimental simulations have a similar trend; however, the numerical plot indicates some deviations from the experimental plot (Jamei et al., 2014). 


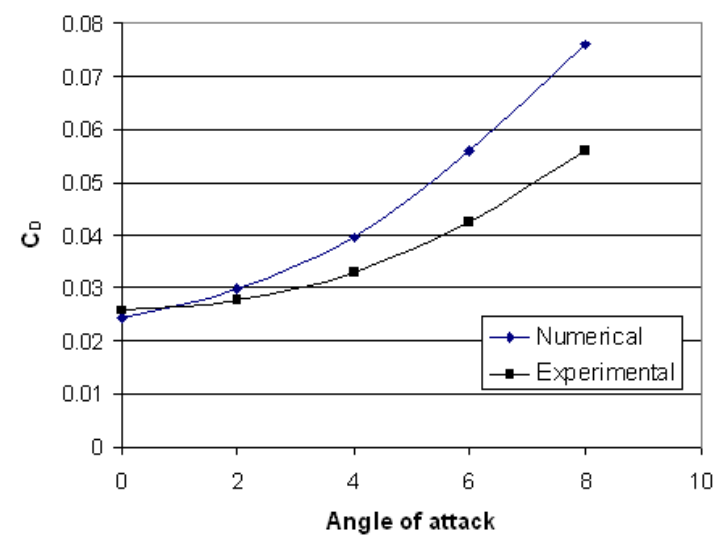

(a) Drag coefficient

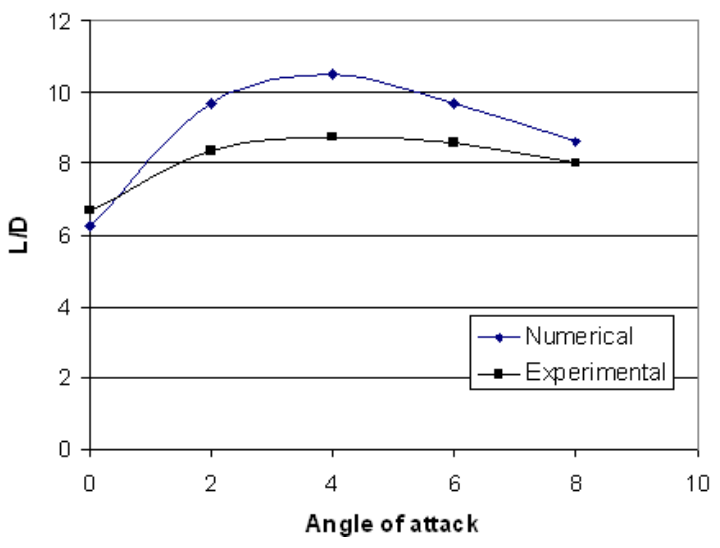

(b) Lift to drag ratio

Figure 2. Comparison of experimental and numerical simulation of the compound wing at ground clearance of 0.15 : (a) drag coefficient; (b) lift to drag ratio.

\section{RESULTS AND DISCUSSION}

\section{Pressure and Velocity Contour of the Compound Wing}

Figures 3-6 show the pressure and velocity distribution of the compound wing for fixed and moving ground at ground clearances of 0.1 and 0.4 with an angle of attack of $4^{\circ}$. For both ground conditions, Figure 3 demonstrates that the ram effect on the lower surface of the compound wing at a ground clearance of 0.1 was stronger than with a ground clearance of 0.4 ; on the other hand, the suction effect on the upper surface at a ground clearance of 0.1 was slightly stronger.

The suction effect at the leading edge of the compound wing for moving ground is greater than for fixed ground at a ground clearance of 0.1 , while there is no difference at a ground clearance of 0.4 (Figure 3 ). There was a wider high pressure area especially near the trailing edge of the lower surface for moving ground at a ground clearance of 0.1 (Figure 3a), which means that the recovery of pressure was slightly higher for moving ground. However, the pressure distribution shows a small increment at the end of the compound wing for fixed ground at a ground clearance of 0.4 (Figure 3b). This figure shows the ground boundary layer's effect on the pressure distributions because of the fixed ground condition.

At a low ground clearance of 0.1 , the effective height for fixed ground is smaller because of its displacement thickness and this causes a vent effect; hence, there was lower pressure in the flow passage between the lower side of the compound wing and ground at the middle span for fixed ground, as shown in Figure 4a. Also, the stagnation point moved to the lower side of the compound wing as the wing approached the ground. Conversely, the vent effect does not exist at a ground clearance of 0.4 , and the displacement thickness related to fixed ground caused slightly higher pressure at the trailing and leading edges compared to moving ground (Figure 4b). 

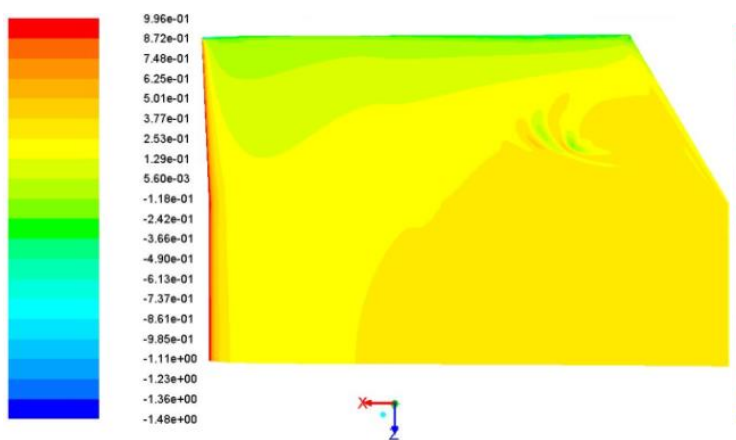

Lower surface- Moving ground
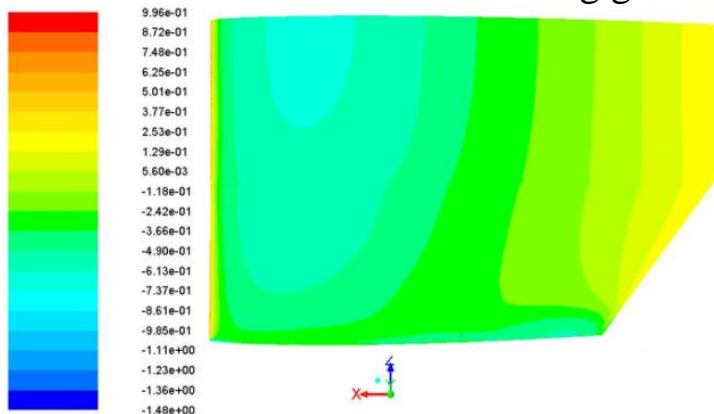

Upper surface- Moving ground

(a) $\mathrm{h} / \mathrm{c}=0.1$
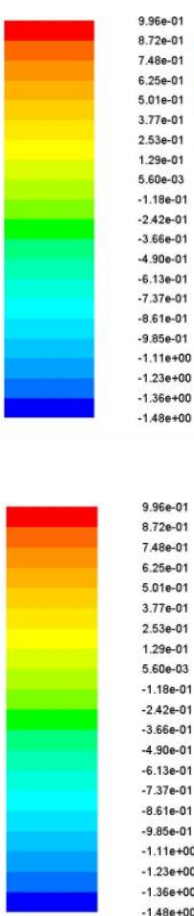

Lower surface- Moving ground

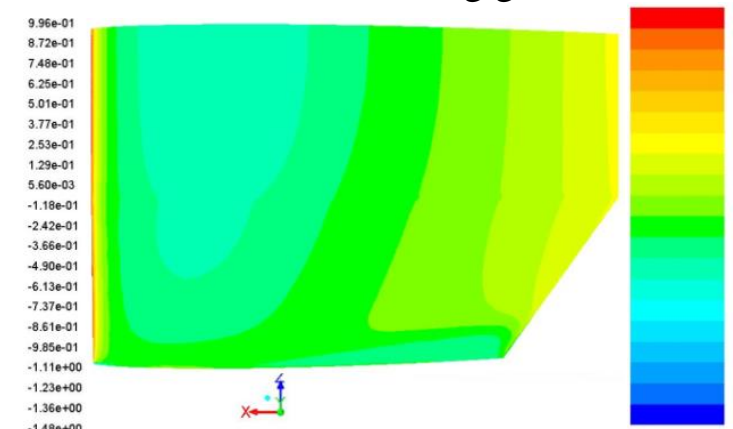

Upper surface- Moving ground
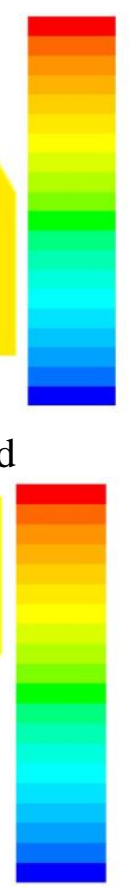

.

\begin{abstract}
.
\end{abstract}

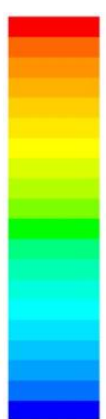

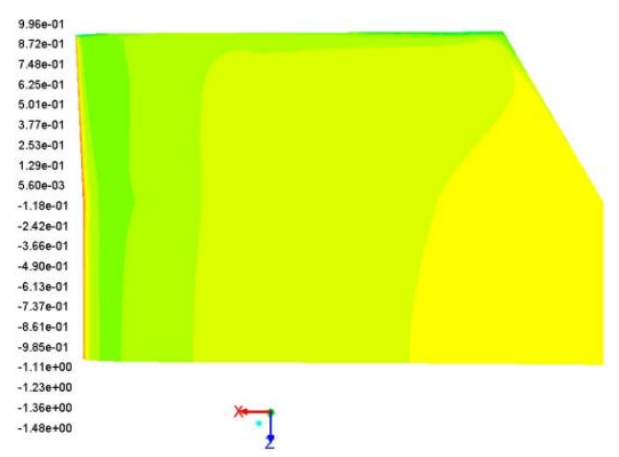

Lower surface- Fixed ground

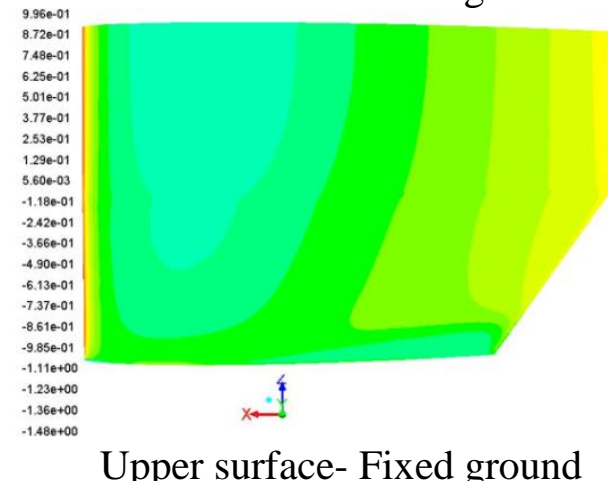

(b) $\mathrm{h} / \mathrm{c}=0.4$

Figure 3. Pressure coefficient contours on upper and lower surfaces of the compound wing for moving and fixed ground with angle of attack of $4^{\circ}$ at (a) $h / c=0.1$; (b) $h / c=0.4$. 


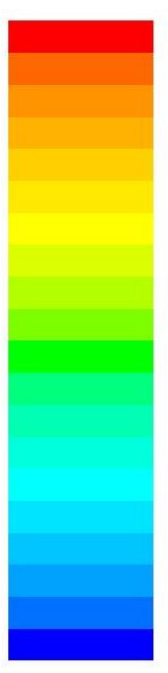

$$
\begin{aligned}
& 9.96 \mathrm{e}-01 \\
& 8.72 \mathrm{e}-01 \\
& 7.48 \mathrm{e}-01 \\
& 6.25 \mathrm{e}-01 \\
& 5.01 \mathrm{e}-01 \\
& 3.77 \mathrm{e}-01 \\
& 2.53 \mathrm{e}-01 \\
& 1.29 \mathrm{e}-01 \\
& 5.60 \mathrm{e}-03 \\
& -1.18 \mathrm{e}-01 \\
& -2.42 \mathrm{e}-01 \\
& -3.66 \mathrm{e}-01 \\
& -4.90 \mathrm{e}-01 \\
& -6.13 \mathrm{e}-01 \\
& -7.37 \mathrm{e}-01 \\
& -8.61 \mathrm{e}-01 \\
& -9.85 \mathrm{e}-01 \\
& -1.11 \mathrm{e}+00 \\
& -1.23 \mathrm{e}+00 \\
& -1.36 \mathrm{e}+00 \\
& -1.48 \mathrm{e}+00
\end{aligned}
$$

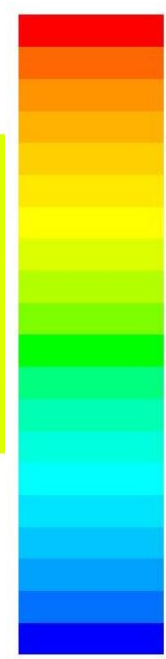

Moving ground

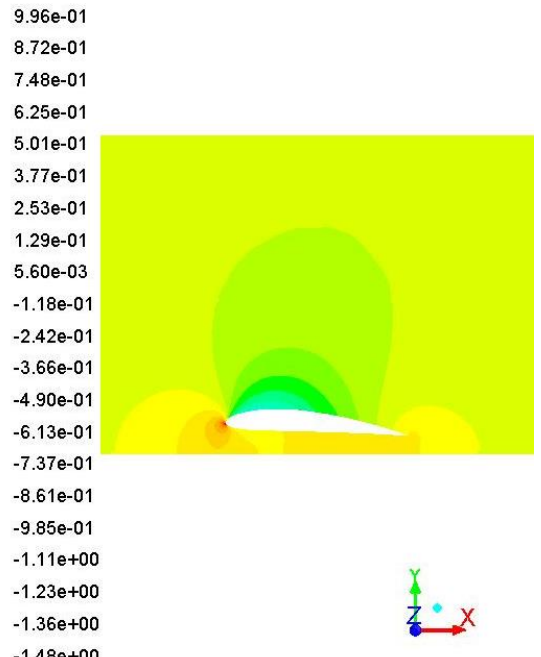

Fixed ground

(a) $\mathrm{h} / \mathrm{c}=0.1$

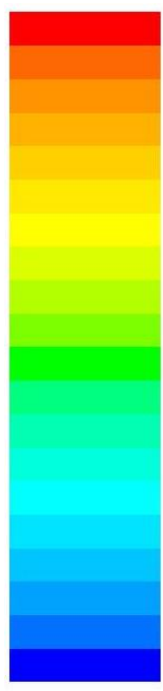

$$
\begin{aligned}
& 9.96 \mathrm{e}-01 \\
& 8.72 \mathrm{e}-01 \\
& 7.48 \mathrm{e}-01 \\
& 6.25 \mathrm{e}-01 \\
& 5.01 \mathrm{e}-01 \\
& 3.77 \mathrm{e}-01 \\
& 2.53 \mathrm{e}-01 \\
& 1.29 \mathrm{e}-01 \\
& \hline 5.60 \mathrm{e}-03 \\
& -1.18 \mathrm{e}-01 \\
& -2.42 \mathrm{e}-01 \\
& -3.66 \mathrm{e}-01 \\
& -4.90 \mathrm{e}-01 \\
& -6.13 \mathrm{e}-01 \\
& -7.37 \mathrm{e}-01 \\
& \hline-8.61 \mathrm{e}-01 \\
& \hline-9.85 \mathrm{e}-01 \\
& \hline-1.11 \mathrm{e}+00 \\
& -1.23 \mathrm{e}+00 \\
& -1.36 \mathrm{e}+00 \\
& -1.48 \mathrm{e}+00
\end{aligned}
$$

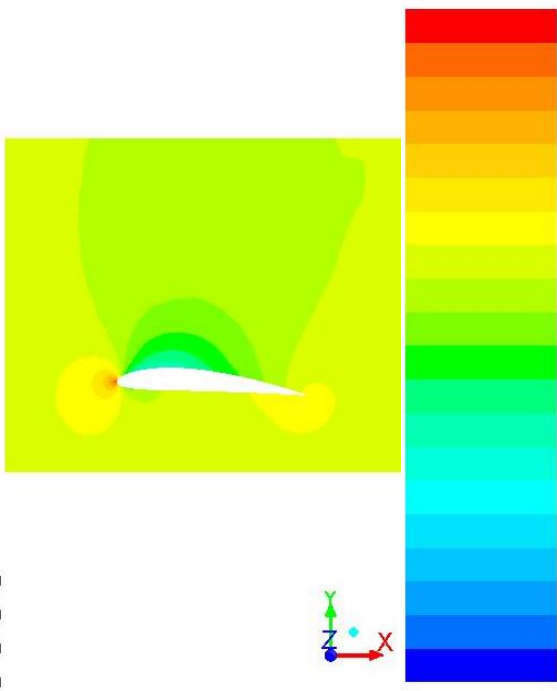

Moving ground

$$
\begin{aligned}
& 9.96 \mathrm{e}-01 \\
& 8.72 \mathrm{e}-01 \\
& 7.48 \mathrm{e}-01 \\
& 6.25 \mathrm{e}-01 \\
& 5.01 \mathrm{e}-01 \\
& 3.77 \mathrm{e}-01 \\
& 2.53 \mathrm{e}-01 \\
& 1.29 \mathrm{e}-01 \\
& \hline 5.60 \mathrm{e}-03 \\
& -1.18 \mathrm{e}-01 \\
& -2.42 \mathrm{e}-01 \\
& -3.66 \mathrm{e}-01 \\
& -4.90 \mathrm{e}-01 \\
& -6.13 \mathrm{e}-01 \\
& -7.37 \mathrm{e}-01 \\
& \hline-8.61 \mathrm{e}-01 \\
& \hline-9.85 \mathrm{e}-01 \\
& \hline-1.11 \mathrm{e}+00 \\
& \hline-1.23 \mathrm{e}+00 \\
& \hline-1.36 \mathrm{e}+00 \\
& -1.48 \mathrm{e}+00
\end{aligned}
$$

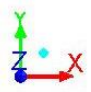

Fixed ground

(b) $\mathrm{h} / \mathrm{c}=0.4$

Figure 4. Pressure coefficient contour on middle span of the compound wing for moving and fixed ground with angle of attack of $4^{\circ}$ at (a) $h / c=0.1 ;$ (b) $h / c=0.4$.

Figure 5 shows the effect of the boundary layer on the velocity distribution in the flow passage between the compound wing and ground. This figure depicts the boundary layers at fixed ground, while they disappeared for moving ground because the speed of the air flow and ground was the same. The velocity distribution at the middle span of the compound wing is in contrast to the pressure distribution (Figure 4a) according to the Bernoulli equation, where there was a higher velocity in the flow passage between the lower surface of the compound wing and fixed ground near the 
leading edge than with moving ground. Figure 6 illustrates the pressure distribution near the wingtips for both conditions. In general, pressure leakages from the lower surface to the upper surface of a wing will generate a tip vortex and spread to the downstream flow field. This vortex is revealed as induced drag. The total drag is a summation of friction drag and induced drag. According to the pressure distribution at the wingtip of the compound wing related to moving ground, the tip vortex was stronger than with fixed ground and therefore the induced drag was greater.
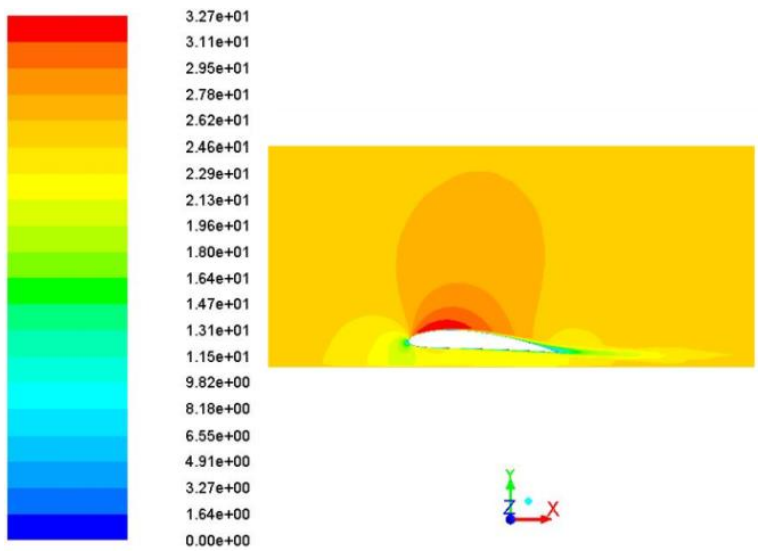

Moving ground

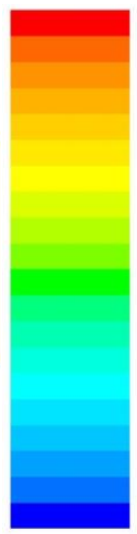

$3.10 e+01$
$2.94 e+01$
$2.77 e+01$
$2.61 e+01$
$2.45 e+01$
$2.28 e+01$
$2.12 e+01$
$1.96 e+01$
$1.79 e+01$
$1.63 e+01$
$1.47 e+01$
$1.31 e+01$
$1.14 e+01$
$9.79 e+00$
$8.16 e+00$
$6.53 e+00$
$4.89 e+00$
$3.26 e+00$
$1.63 e+00$
$0.00 e+00$

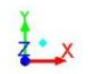

Fixed ground

Figure 5. Velocity contour $(\mathrm{m} / \mathrm{s})$ on middle span of the compound wing for moving and fixed ground with angle of attack of $4^{\circ}$ at $h / c=0.1$.

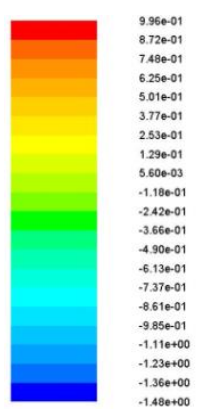

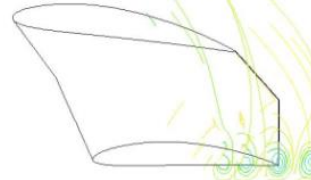

$\sum_{z}^{x}$

Moving ground

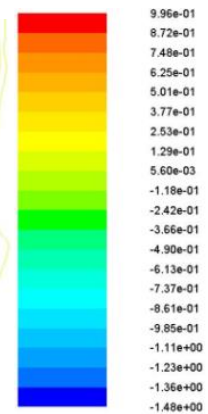

$-1.360+200$

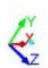

Fixed ground

Figure 6. Pressure coefficient contours near wingtip of the compound wing for moving and fixed ground with angle of attack of $4^{\circ}$ at $h / c=0.1$.

\section{Aerodynamic Coefficients of the Compound Wing}

\section{Lift Coefficient}

The effects of different ground clearance on the aerodynamic coefficients of the compound wing for moving and fixed ground at an angle of attack of $4^{\circ}$ are shown in 
Tables 2-6 and Figures 7-9. Figure 7 illustrates a rapid increase in the lift coefficients of the compound wing for both ground conditions as the ground clearance was decreased. According to the present results, at low ground clearance $(\mathrm{h} / \mathrm{c}<0.15)$ the lift coefficient shows a greater improvement related to moving ground, while at a ground clearance greater than 0.15 the lift coefficient of the compound wing is higher when the ground is assumed to be fixed. This figure reveals the effect of ground viscous varied versus ground clearance. The increment of the lift coefficient of the compound wing with moving ground compared with fixed ground was calculated by using Eq. (4) and is summarized in Table 2. The increment was valuable at a small ground clearance, where at the ground clearance of 0.1 , it was $3.5 \%$.

$$
\operatorname{Increment}(\%)=\frac{C_{L(\text { Moving })}}{C_{L(\text { Fixed })}}-1
$$

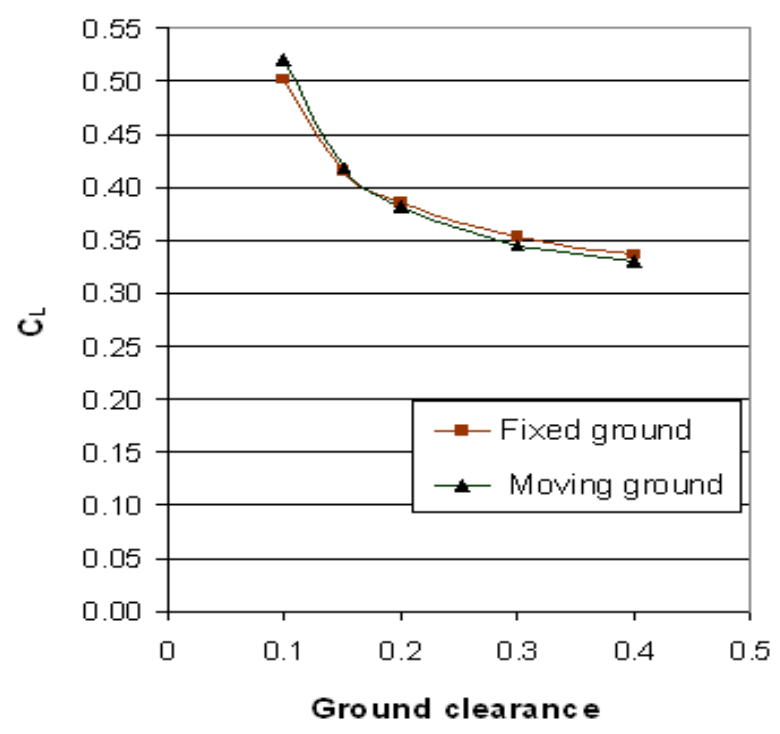

Figure 7. Lift coefficient $\left(C_{L}\right)$ versus ground clearance at angle of attack of $4^{\circ}$.

Table 2. Lift coefficient and its increment of the compound wing versus ground clearance at angle of attack of $4^{\circ}$ for moving and fixed ground.

\begin{tabular}{cccc}
\hline \multirow{2}{*}{ Ground clearance } & \multicolumn{2}{c}{ Lift coefficient } & \multirow{2}{*}{ Increment of } \\
\cline { 2 - 3 } & $\mathrm{C}_{\mathrm{L}}(\%)$ \\
\cline { 2 - 3 } & Moving ground & Fixed ground & \\
\hline 0.1 & 0.519 & 0.502 & 3.5 \\
0.15 & 0.418 & 0.416 & 0.5 \\
0.2 & 0.381 & 0.385 & -1.1 \\
0.3 & 0.345 & 0.353 & -2.4 \\
0.4 & 0.330 & 0.337 & -2.3 \\
\hline
\end{tabular}

\section{Drag Coefficient}

The drag coefficients of the compound wing versus ground clearance for moving and fixed ground are depicted in Figure 8. In addition, the differences of drag coefficient of the compound wing related to different ground boundaries were calculated by using Eq. (5) in Table 3. Figure 8 shows a small variation in the drag coefficient of both ground 
conditions versus ground clearance, while the plot of moving ground was lower than fixed ground. The gap between the plots reduced when the ground clearance increased. The reduction of the drag coefficient related to moving ground as compared with fixed ground was in the range 4.6-2.1\%, as shown in Table 3. This reduction could be related to viscous drag.

$$
\operatorname{Reduction}(\%)=1-\frac{C_{D(\text { Moving })}}{C_{D(\text { Fixed })}}
$$

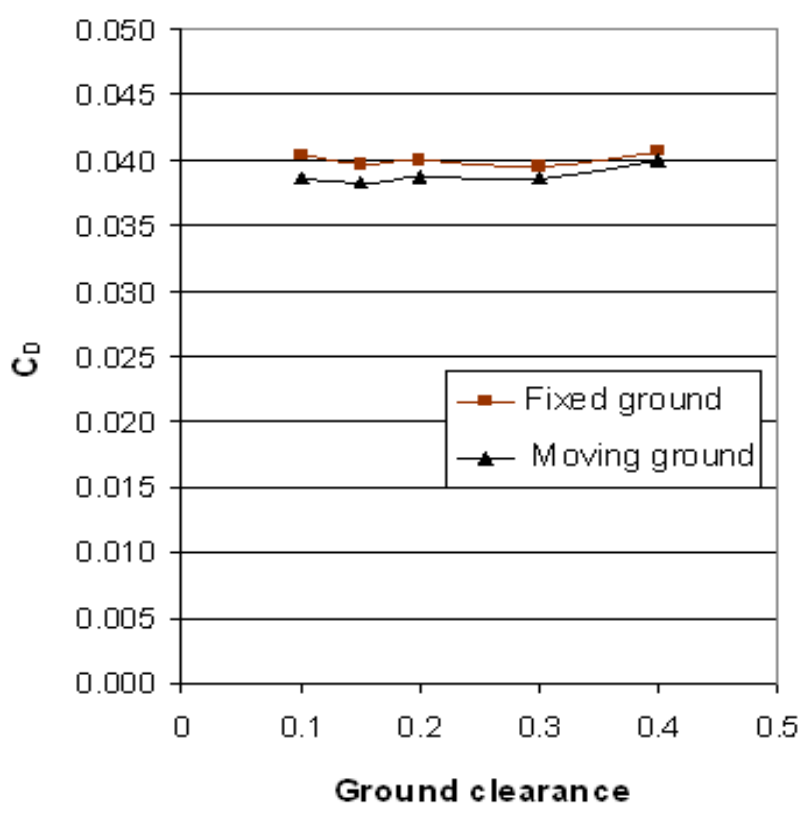

Figure 8. Drag coefficient (Kaptan, Buyruk, \& Ecder) versus ground clearance at angle of attack of $4^{\circ}$.

Table 3. Drag coefficient and its reduction of the compound wing versus ground clearance at angle of attack of $4^{\circ}$ for moving and fixed ground.

\begin{tabular}{cccc}
\hline \multirow{2}{*}{$\begin{array}{c}\text { Ground } \\
\text { clearance }\end{array}$} & \multicolumn{2}{c}{ Drag coefficient } & Reduction of \\
\cline { 2 - 3 } & $\begin{array}{c}\text { Moving } \\
\text { ground }\end{array}$ & Fixed ground & $\mathrm{C}_{\mathrm{D}}(\%)$ \\
\hline 0.1 & 0.039 & 0.0405 & 4.6 \\
0.15 & 0.038 & 0.0397 & 3.5 \\
0.2 & 0.039 & 0.0400 & 3.1 \\
0.3 & 0.039 & 0.0395 & 2.1 \\
0.4 & 0.040 & 0.0407 & 1.8 \\
\hline
\end{tabular}

\section{Lift to Drag Ratio}

The lift to drag ratio of the compound wing versus ground clearance is summarized in Table 4. In addition, the increment of the lift to drag ratio of the compound wing for moving ground compared with fixed ground was determined by using Eq. (6). The 
increment was noticeable at low ground clearances. For example, at a ground clearance of 0.1 , the increment was $8.4 \%$. The trend of the lift to drag ratio of the compound wing for both ground boundaries versus ground clearance is shown in Figure 9. This figure illustrates that the efficiency (lift to drag ratio) of the compound wing was affected by the ground viscous effect at ground clearances lower than 0.2 .

$$
\operatorname{Increment}(\%)=\frac{L / D_{(\text {Moving })}}{L / D_{(\text {Fixed }))}}-1
$$

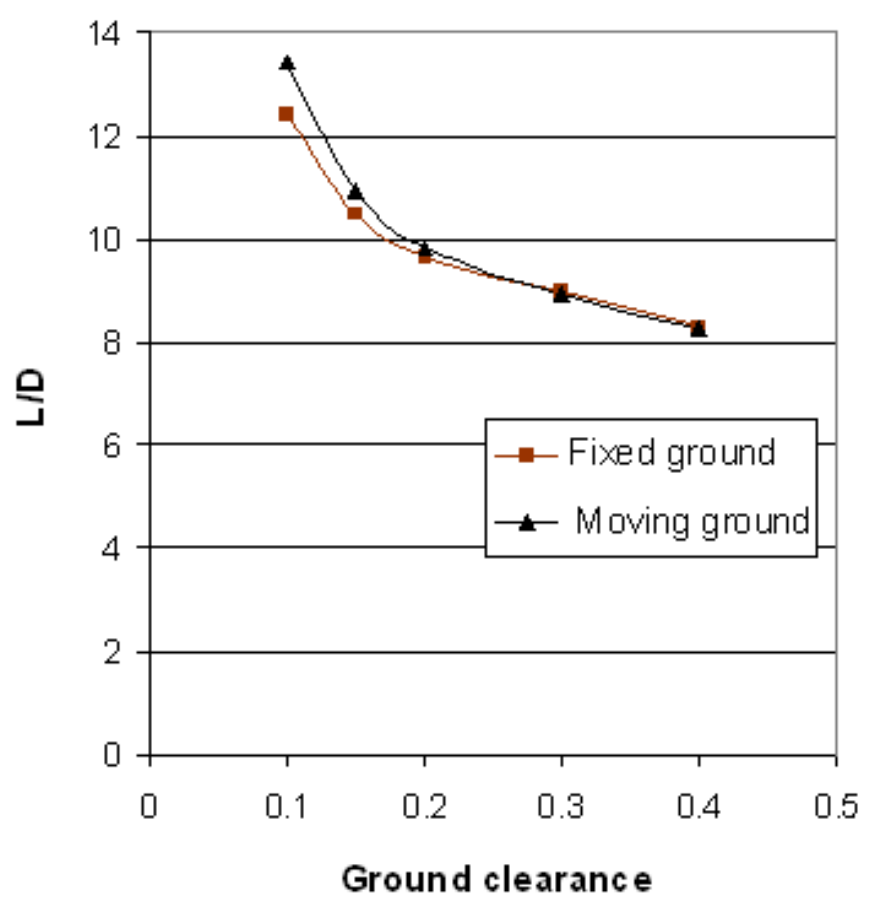

Figure 9. Lift to drag ratio (L/D) versus ground clearance at angle of attack of $4^{\circ}$. Table 4. Lift to drag ratio and its increment of the compound wing versus ground clearance at angle of attack of $4^{\circ}$ for moving and fixed ground.

\begin{tabular}{cccc}
\hline \multirow{2}{*}{$\begin{array}{c}\text { Ground } \\
\text { clearance }\end{array}$} & \multicolumn{2}{c}{ Lift to drag ratio } & Increment of \\
\cline { 2 - 3 } & $\begin{array}{c}\text { Moving } \\
\text { ground }\end{array}$ & Fixed ground & \\
\hline 0.1 & 13.436 & 12.39 & 8.4 \\
0.15 & 10.917 & 10.48 & 4.2 \\
0.2 & 9.823 & 9.63 & 2.0 \\
0.3 & 8.920 & 8.94 & -0.3 \\
0.4 & 8.249 & 8.29 & -0.5 \\
\hline
\end{tabular}

\section{Moment Coefficient and Center of Pressure}

The variation of moment coefficients of the compound wing versus ground clearance is shown in Table 5. A moment coefficient that caused a decrease in the angle of attack was defined as a positive moment. The increment of moment coefficient related to 
ground boundaries was calculated by using Eq. (7) in Table 5. There is a slight variation in increment, and the maximum increment was $2.5 \%$ at a ground clearance of 0.1 . In Table 6, the increment of the distance of the center of pressure from the leading edge of the compound wing related to moving ground was calculated by using Eq. (8). This increment was small. Based on the present results, the stability of the compound wing is not affected by the type of ground boundary.

$$
\begin{gathered}
\text { Increment }(\%)=\frac{C_{M(\text { Moving })}}{C_{M(\text { Fixed })}}-1 \\
\text { Increment }(\%)=\frac{X_{C P} / c_{(\text {Moving })}}{X_{C P} / c_{(\text {Fixed })}}-1
\end{gathered}
$$

Table 5. Moment coefficient and its increment of the compound wing versus ground clearance at angle of attack of $4^{\circ}$ for moving and fixed ground.

\begin{tabular}{cccc}
\hline \multirow{2}{*}{$\begin{array}{c}\text { Ground } \\
\text { clearance }\end{array}$} & \multicolumn{2}{c}{ Moment coefficient } & Increment of \\
\cline { 2 - 4 } & $\begin{array}{c}\text { Moving } \\
\text { ground }\end{array}$ & Fixed ground & $\mathrm{C}_{\mathrm{M}}(\%)$ \\
\hline 0.1 & 0.074 & 0.073 & 2.5 \\
0.15 & 0.061 & 0.061 & 1.1 \\
0.2 & 0.057 & 0.057 & 0.0 \\
0.3 & 0.051 & 0.052 & -1.0 \\
0.4 & 0.047 & 0.047 & -1.0 \\
\hline
\end{tabular}

Table 6. Center of pressure and its increment of the compound wing versus ground clearance at angle of attack of $4^{\circ}$ for moving and fixed ground.

\begin{tabular}{cccc}
\hline \multirow{2}{*}{$\begin{array}{c}\text { Ground } \\
\text { clearance }\end{array}$} & \multicolumn{2}{c}{ Center of pressure } & Increment of \\
\cline { 2 - 3 } & $\begin{array}{c}\text { Moving } \\
\text { ground }\end{array}$ & Fixed ground & $\mathrm{X}_{\mathrm{CP}} / \mathrm{c}(\%)$ \\
\hline 0.1 & 0.393 & 0.394 & -0.3 \\
0.15 & 0.396 & 0.395 & 0.2 \\
0.2 & 0.399 & 0.397 & 0.4 \\
0.3 & 0.397 & 0.395 & 0.5 \\
0.4 & 0.392 & 0.390 & 0.5 \\
\hline
\end{tabular}

\section{CONCLUSIONS}

The flow structure and the aerodynamic coefficients of a compound wing in the ground effect were numerically investigated with respect to fixed and moving ground. Excellent performance of the compound wing with a small ground clearance was demonstrated for both ground conditions $(\mathrm{h} / \mathrm{c}<0.2)$. The lift and drag coefficients of the compound wing showed some differences because of the ground viscous effect related to fixed ground as compared with moving ground. As a result, the lift to drag ratio of the compound wing had considerable variation at low ground clearances. Therefore, the ground viscous effect could be more significant for the compound wing than for conventional wings. 
However, the moment coefficient and center of pressure of the compound wing are not affected by the type of ground boundary, so it can be concluded that the stability of the compound wing has no more variations. Based on the pressure and velocity contours for both ground boundaries, the flow structure around the compound wing varied due to the ground viscous effect. The moving ground does not exist in some wind tunnels. Therefore, this research confidently helps give a better understanding of the ground viscous effect on the wing-in-ground effect and can modify the results of wind tunnels because, in reality, for zero air velocity there is no ground viscous effect.

\section{ACKNOWLEDGMENTS}

The authors would like to thank the Ministry of Science, Technology, and Innovation (MOSTI) Malaysia for funding this research.

\section{REFERENCES}

Abramowski, T. (2007). Numerical investigation of airfoil in ground proximity. Journal of Theoretical and Applied Mechanics, 45, 425-436.

Barber, T. J., Leonardi, E., \& Archer, R. (2002). Causes for discrepancies in ground effect analyses. Aeronautical Journal, 106, 653-667.

Borello, G., Ferro, S., Limone, S., Ferro, G., Bergamini, P., \& Quagliotti, F. (1999). The role of the moving ground for automotive wind tunnel testing on race cars. Training, 2009, 04-01.

Jamei, S., Maimun, A., Mansor, S., Azwadi, N., \& Priyanto, A. (2011). Numerical investigation on performance and environmental impact of a compound wing in ground effect. Paper presented at the 2 nd International Conference on Fluid Mechanics and Heat Transfer.

Jamei, S., Maimun, A., Mansor, S., Azwadi, N., \& Priyanto, A. (2012). Numerical investigation on aerodynamic characteristics of a compound wing-in-ground effect. Journal of Aircraft, 49(5), 1297-1305.

Jamei, S., Maimun, A., Mansor, S., Priyanto, A., Azwadi, N., \& Mobassher Tofa, M. (2014). Aerodynamic behavior of a compound wing configuration in ground effect. Jurnal Teknologi, 66(2), 21-27.

Kaptan, Y., Buyruk, E., \& Ecder, A. (2008). Numerical investigation of fouling on cross-flow heat exchanger tubes with conjugated heat transfer approach. International Communications in Heat and Mass Transfer, 35(9), 1153-1158.

Knowles, K., Donoghue, D., \& Finnis, M. (1994). A study of wings in ground effect. Paper presented at the Loughborough University Conference on Vehicle Aerodynamics.

Launder, B. E., \& Spalding, D. (1974). The numerical computation of turbulent flows. Computer Methods in Applied Mechanics and Engineering, 3(2), 269-289.

Ludwig, R. D., McGregor, R. G., Blowes, D. W., Benner, S. G., \& Mountjoy, K. (2002). A permeable reactive barrier for treatment of heavy metals. Ground Water, 40(1), 59-66.

Marqués-Bruna, P. (2011). Engineering the race car wing: Application of the vortex panel numerical method. Sports Engineering, 13(4), 195-204.

Marshall, D., Newman, S., \& Williams, C. (2010). Boundary layer effects on a wing in ground-effect. Aircraft Engineering and Aerospace Technology, 82(2), 99-106. 
Saad, I., \& Bari, S. (2013). Cfd investigation of in-cylinder air flow to optimize number of guide vanes to improve ci engine performance using higher viscous fuel. International Journal of Automotive and Mechanical Engineering, 8, 10961107.

Shih, T.-H., Liou, W. W., Shabbir, A., Yang, Z., \& Zhu, J. (1995). A new k- $\varepsilon$ eddy viscosity model for high reynolds number turbulent flows. Computers \& Fluids, 24(3), 227-238.

Tahseen, T. A., Ishak, M., \& Rahman, M. M. (2013). Laminar forced convection heat transfer over staggered circular tube banks: A cfd approach. Journal of Mechanical Engineering and Sciences, 4, 418-430.

Yang, W., Lin, F., \& Yang, Z. (2010). Three-dimensional ground viscous effect on study of wing-in-ground effect. Paper presented at the The third international conference on modelling and simulation (ICMS2010), Wuxi.

Yang, W., \& Yang, Z. (2009). Aerodynamic investigation of a 2d wing and flows in ground effect. Chinese Journal of Computational Physics, 2, 008.

Yang, Z. G., Yang, W., \& Jia, Q. (2010). Ground viscous effect on $2 \mathrm{~d}$ flow of wing in ground proximity. Eng. Appl. Computational Fluid Mechanics 4(4), 521-531.

Ying, C., Yang, W., \& Yang, Z. (2010a). Ground viscous effect on stall of wing in ground effect. Proceedings of 3rd International Conference on Modeling and Simulation, Modeling and Simulation in Industrial Application, 3, 230-233.

Ying, C., Yang, W., \& Yang, Z. (2010b). Numerical simulation on stall of wing in ground effect. Flight Dynamics, 28(5), 9-12.

Yun, L., Bliault, A., \& Doo, J. (2009). Wig craft and ekranoplan: Ground effect craft technology. New York: Springer.

\section{NOMENCLATURES}

\begin{tabular}{|c|c|}
\hline $\mathrm{a}$ & Anhedral angle \\
\hline $\mathrm{b}$ & Wing span \\
\hline $\mathrm{bm}$ & Middle wing span \\
\hline $\mathrm{c}$ & Chord length \\
\hline $\mathrm{C}_{\mathrm{D}}$ & Drag coefficient \\
\hline $\mathrm{C}_{\mathrm{L}}$ & Lift coefficient \\
\hline$c_{t}$ & Tip chord length \\
\hline $\mathrm{D}$ & Drag force \\
\hline $\mathrm{G}_{\mathrm{b}}$ & $\begin{array}{l}\text { Generation of turbulence kinetic } \\
\text { energy due to buoyancy }\end{array}$ \\
\hline $\mathrm{G}_{\mathrm{k}}$ & $\begin{array}{l}\text { Generation of turbulence kinetic } \\
\text { energy due to the mean velocity } \\
\text { gradients }\end{array}$ \\
\hline $\mathrm{h}$ & $\begin{array}{l}\text { Height of trailing edge above the } \\
\text { ground }\end{array}$ \\
\hline
\end{tabular}

$\mathrm{h} / \mathrm{c} \quad$ Ground clearance

$k \quad$ Turbulent kinetic energy

L Lift force

L/D Lift to drag ratio

S Wing planform area

Sij Mean rate of deformation tensor

$\mathrm{U} \quad$ Free stream mean velocity

$\mathrm{u}_{\mathrm{j}} \quad$ Velocity in $\mathrm{j}$-th direction

$\mathrm{Y}_{\mathrm{M}}$ Effects of compressibility on turbulence

$\varepsilon \quad$ Turbulent energy dissipation rate

$\lambda \quad$ Taper ratio $(\mathrm{c} / \mathrm{ct})$

$\mu \quad$ Air viscosity

$\mu_{\mathrm{t}} \quad$ Turbulent viscosity

$\rho \quad$ Air density 